
ric tensor.

I conclude that our drawing of the observational-thefretical line at any given point is an accident and a function of our physiological make-up, our current state of knowledge, and the instruments we happen to have available and, therefore, that it has no ontological significance whatever.

$$
\star \star \star
$$

NOTES 1. E. Nagel, The Structure of Science (New
York: Harcourt, Brace, and World, 1961), Chap. vi.

2. For the genesis and part of the content of some of the ideas expressed herein, I am indeinfluential are H. Feigl "Existential Hypo more Philosophy of Science XVII (1950) 35-62; P. K. Feyerabend, "An Attempt at a R pretation of Experience" Proceeding of the Anterpretation of Experience," Proceeding of the Aristotelian Society, LVIII (1958), 144-70; N. R. Hanson, Patterns of Discovery (Cambridge:
Cambridge University Press, 1958); E. Nagel, loc. cit.; Karl Popper, The Logic of Scientific Discovery
(London: Hutchinson, 1959); M. Scriven, "Definitions, Explanations, and Theories," in Minnesota Studies in the Philosophy of Science, eds. H.
Feigl, M. Scriven, and G. Maxwell, Vol. II (Minneapolis: University of Minnesota Press, 1958); Wilfrid Sellars, "Empiricism and the Philosophy of Mind," in Minnesota Studies in the Philosophy of Science, eds. H. Feigl and M. Scriven, Vol. I (Minneapolis: University of Minnesota Press, 1956), and "The Language of Theories," in Current Issues in the Philosophy of Science, eds. $\mathrm{H}$. Feigl and G. Maxwell (New York: Holt, Rinehart, and Winston, 1961).

3. I have borrowed the hammer analogy from E. Nagel, "Science and [Feigl's] Semantic Realism," Philosophy of Science, XVII (1950), 174-81 but it should be pointed out that Professor Nagel makes it clear that he does not necessarily subscribe to the view which he is explaining. ics, II (1943), 248-58, 335-42, reprinted in Readings in the Philosophy of Science, eds. H. Feigl and Brodbeck (New York: Appleton-Century-

5. I am not attributing to Professor Bergmann the absurd views suggested by these laestions. He seems to take a sense-datum what he called "the empirical hierarchy") some ways, such a position is more difficult refute than one which purports to take "observable-physical-object" view. However, believe that demolishing the straw men with which I am now dealing amounts to desirable preliminary "therapy." Some nonrealist interpretations of theories which embody the presupposition that the observable-theoretical distinction is sharp and ontologically crucial seem to me to entail positions which correspond to such straw men rather closely.

6. For arguments that it is possible to alter theory without altering the meaning of its terms, see my "Meaning Postulates in Scientific Theories," in Current Issues in the Philosophy of Science, eds. Feigl and Maxwell. 7. The reader is no doubt familiar with the
abundant literature concerned with this issue See, for example, Sellars's "Empiricism and the Philosophy of Mind," which also contains references to other pertinent works.

8. We may say "noninferentially" decide, provided this is interpreted liberally enough to avoid starting the entire controversy about observability all over again.

9. Cf. Sellars, "Empiricism and the Philosophy of Mind." As Professor Sellars points out, Sensations and inner states (relative to problem. subjective observation language, I would interare theoretical entities (and they "really exist") and not merely actual and/or possible behavior. Surely it is the unwillingness to countenance theoretical entities-the hope that every sentence is translatable not only into some observation language but into the physical-thing languagewhich is responsible for the "logical behaviorism" of the neo-Wittgensteinians.

\title{
DO WE SEE THROUGH A MICROSCOPE?
}

A couple of years ago I was discussing scientific realism with Dr. Jal Parakh, a biologist from Western Washington University. We had talked about many of the things that philosophers find important. He diffidently added that, from his point of view, a main reason for believing in the existence of entities postulated by theory is that we have evolved better and better ways of actually seeing them. I began to protest against this naive instinct that bypasses the philosophical issues, but I had to stop. Isn't what he says right?

Last fall, during a lecture in Stanford University's "Microscopy for Biologists" course, the professor, Dr. Paul Green, casually remarked that "X-ray diffraction microscopy is now the main interface between scopy is now the main interface between Green is a nuts and bolts man, not given to Green is a nuts and bolts man, not given to
philosophizing. Philosophers of science who discuss realism and anti-realism must need know a little about the instruments that inspire such eloquence. What follows is first start, which limits itself to biology and which hardly gets beyond the light microscope. Even that is a marvel of marvels which, I suspect, not many philosophers well understand. Microscopes do not work in the way that most untutored people supin the way that most untutored people suppose. But why, it may be asked, should philosopher care how they work? Because correct understanding is necessary to elucidate problens of scientific realism as well as answering the question posed by my title.

Reprinted by permission from Pacific Philosophica
Our philosophical literature is full of intriate accounts of causal theories of percepthey have curiously little to do with real life. We have fantastical descriptions of berrant causal chains which, Gettier-style, all in question this or that conceptual analyis. But the modern microscopist has far more amazing tricks than the most imaginative of armchair students of perception. What we require in philosophy is better awareness of the truths that are stranger than fictions. We ought to have some understanding of those astounding physical systems "by whose augmenting power we now tems "by whose augmenting power we now before." 1

THE GREAT CHAIN OF BEINC

Philosophers have written dramatically about telescopes. Galileo himself invited philosophizing when he claimed to see the moons of Jupiter, assuming that the laws of (n) vision in the celestial sphere are the same as vas that very case to urge that great science proceeds as much by propaganda as by reason: Galileo was a con man, not an experimental reasoner. Pierre Duhem used the telescope to present his famous thesis that no theory need ever be rejected, for phenomena that don't fit can always be accommodated by changing auxiliary hypotheses (if the stars aren't where theory predicts, blame the telescope, not the heavens). By comparison the microscope has played a humble role, seldom used to generate philosophical para- 
dox. Perhaps this is because everyone expected to find worlds within worlds here on earth. Shakespeare is merely an articulate poet of the great chain of being when $h$ writes of Queen Mab and her minute coach "drawn with a team of little atomies ... her waggoner, a small grey coated gnat not half so big as a round little worm prick'd from
the lazy finger of a maid."2 One expected tinies beneath the scope of human vision. When dioptric glasses were to hand, the laws of direct vision and refraction went unquestioned. That was a mistake. I suppose no one understood how a microscope works before Ernst Abbe (1840-1905). One immediate reaction, by a president of the Royal Microscopical Society, and quoted for years in many editions of the standard American textbook on microscopy, was that we do not, after all, see through a microscope. The theoretical limit of resolution

[A] Becomes explicable by the research of Abbe It is demonstrated that microscopic vision is sui generis. There is and there can be no comparison between microscopic and macroscopic vision. The images of minute objects are not delineated microscopically by means of the ordinary laws of depend entirely on the laws of diffraction. ${ }^{3}$

I think that means that we do not see, in any ordinary sense of the word, with a microscope.

\section{PHILOSOPHERS OF THE}

MICROSCOPE

Every twenty years or so a philosopher has said something about microscopes. As the
spirit of logical positivism came to America, one could read Gustav Bergman telling us that as he used philosophical terminology,

. microscopic objects are not physical things in a literal sense, but merely by courtesy of language and pictorial imagination. . . . When 1 look through a microscope, all $I$ see is a patch of color which creeps through the field like due course Grover Maxwell, denying that there is any fundamental distinction between observational and theoretical entities, urged a continuum of vision: "looking through a window pane, looking through glasses, looking through binoculars, looking through a low power microscope, looking through a high power microscope, etc." 5 Some entities may be invisible at one time and later, thanks to a new trick of technology, they become observable. The distinction between the observable and the merely theoretical is of no interest for ontology. Grover ontology.

Grover Maxwell was urging a form of scientific realism. He rejected any anti-realism that holds that we are to believe in the existence of only the observable entities that are entailed by our theories. In his new antirealist book The Scientific Image, Bas van Fraassen strongly disagrees. He calls his philosophy constructive empiricism. He holds that "Science aims to give us theories which are empirically adequate; and acceptance of a theory involves as belief only that it is empirically adequate." "Six pages later he attempts this gloss: "To accept a theory is (for us) to believe that it is empirically adequate that what the theory says about what is oberuate what the theory says about what is observable (by us) is true." Clearly then it is essential for van Fraassen to restore the distinction between observable and unobservable. Bu it is not essential to him, exactly where we should draw it. He grants the "observable" is a vague term whose extension itself may be determined by our theories. At the same time, he wants the line to be drawn in the place which is, for him, most readily defensible, so that even if he should be pushed back a bit in the course of debate, he will still have lots left on the "unobservable" side of the fence. He distrusts Grover Maxwell's continuum and tries to stop the slide from seen to inferred entities as early as poside

He quite rejects the ideas of a consus.

There rects the idea of a continuum.

There are, says van Fraassen, two quite distinct kinds of case arising from Grove Maxwell's list. You can open the window and see the fir tree directly. You can walk up to at least some of the objects you see through binoculars and see them in the round, with the naked eye. (Evidently he is not a bird watcher.) But there is no way to see a blood platelet with the naked eye. The passage from a magnifying glass to even a low-powered microscope is the passage from what we might be able to observe with the eye unaided, to what we could not observe except with instruments. Van Fraassen concludes that we do not see through a microscope. Yet we see through through a microscope. look at the moons, but we cannot shrink to look at the moons, but we cannot shrink to the size of a paramecium and look at it. He also compares the vapor trail made by a jet and the ionization track of an electron in a cloud chamber. Both result from similar physical processes, but you can point ahead of the trail and spot the jet, or at least wait for it to land, but you can never wait for the electron to land and be seen.

Taking van Fraassen's view to the extreme you would say that you have observed or seen something by the use of an optical instrument only if human beings optical instrument vision if human beings with fairly nin with the naked eye seen that very thing with the naked eye. The ironist will retort. "What's so great about 20-20 human vision?" It is doubless of some small interest to know the limits of the naked eye, just as it is a challenge to climb a rock face without pitons or Everest without oxygen. But if you care chiefly to get to the top you will use all the tools that are handy. Observation, in my book of science, is not passive seeing. Observation is a skill. Any skilled artisan cares for new tools. I elsewhere use Caroline Herschel to illustrate the supremely skilled observer. ${ }^{7}$ She discovered more comets than anyone, using a rather simple tool, a sky sweeper, using a rather up by the telescopes of her and was William Hether Waw com Herschel. Our confidence that she saw comets has, contrary to van Fraassen, nothing to do with a fiction of getting up close and seeing that they are indeed comets-that's still impossible. To understand whether she was seeing, or whether one sees through the microscope, one needs to know quite a lot about the tools.
JUST PEER: INTERFERE

Philosophers tend to look on microscopes as black boxes with a light source at one end and a hole to peer through at the other. There are, as Grover Maxwell puts it, low power and high power microscopes, more and more of the same kind of thing. That's not right nor are microscopes just for looking through. In fact a philosopher will toing has draw Thur Thurber, draw his own reflected eyeball, or, like Gustav Bergman, see only "a patch of color which creeps through the field like a shadow over a wall." He will certainly not be able to tell a dust particle from a fruit fly's salivary gland until he has started to dissect a fruit fly under a microscope of modest magnification.

That is the first lesson: you learn to see through a microscope by doing, not just by looking. There is a parallel to Berkeley's New Theory of Vision according to which we have three-dimensional vision only we learning what it is like to move around in he world and intervene in it. Tacile sense is correlated with our allegedly two dime is ional retinal image and his learned cuenproduce produces three-dimensional perception. Likewise a scuba diver learns to see in the new medium of the oceans only by swimming around. Whether or not Berkeley was right about primary vision, new ways of seeing, acquired after infancy, involve learning by doing, not just passive looking. The conviction that a particular part of a cell is there as imaged is, to say the least. ceinforced straightforward physical means, you microinject a fluid into Just that part of the cell. We see the tiny glass needle-a tool that we have ourselves hand crafted under the microscope-jerk through the cell wall. We see the lipid oozing out of the end of the needle as we gently turn the micrometer screw on a large, thoroughly macroscopic, plunger. Blast! Inept as I am, I have just burst the cell wall, and must try again on another specimen. John 
Dewey's jeers at the "spectator theory of knowledge" are equally germane for the spectator theory of microscopy.

This is not to say that practical microscopists are free from philosophical peravailable textbooks intended for biologists:

[B] The microscopist can observe a familiar object in a low power microscope and see slightly enlarged image which is "the same as" the object. Increase of magnification may reveal details in the object which are invisible to th naked eye; it is natural to assume that they, also, are "the same as" the object. (At this stage it is necessary to establish that detail is not a consequence of damage to the specimen durin preparation for microscopy.) But what is actually same as the object"?

Obviously the image is a purely optical effect. ... The "sameness" of object and image in fact implies that the physical interactions with the light beam that render the object visible to the eye (or which would render it visible, if large enough) are identical with those that lead to formation of an image in the microscope.

Suppose however, that the radiation used to form the image is a beam of ultraviolet light, $x$ rays, or electrons, or that the microscope

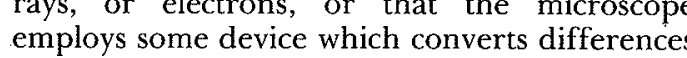
in phase to changes in intensity. The image then cannot possibly be "the same" as the object, even in the limited sense just defined! The eye is unable to perceive ultraviolet, $\mathrm{x}$-ray, or electron radiation, or to detect shifts of phase between light beams.

This line of thinking reveals that the image must be a map of interactions between the specime and the imaging radiation. 8

The author goes on to say that all of the methods she has mentioned, and more, "can produce 'true' images which are, in some sense, 'like' the specimen." She also remark that in a technique like the radioautogram "one obtains an 'image' of the specimen ... obtained exclusively from the point of view of the location of radioactive atoms. This type of 'image' is so specialized as to be, genadditional image, the photomicrograph upon which it is superposed."
This microscopist is happy to say that we
through a microscope onlv when the physical interactions of specimen and light beam are "identical" for image formation in the microscope and in the eye. Contrast my quotation [A] from an earlier generation, which holds that since the ordinary light microscope works by diffraction, it is not the microscopis microscopists [A] and [B] who disagree about the simplest light microscope possibly "be on the right philosophical track about "seeing"? The scare quotes around "image" and "true" suggest more ambivalence in [B]. One should be especially wary of the word "image" in microscopy. Sometimes it denotes something at which you can point, a shape cast on a screen, a micrograph, or whatever. But on other occasions it denotes as it were the input to the eye itself. The conflation results from geometrical optics, in which results from geometrical optics, in which one diagrams the system with a specimen in focus and an "image" in the (cher "image" ind cates what you will see if you place your eye there. I do resist one inference that might be drawn even from quotation [B]. It may seem that any statement about what is see with a microscope is theory-loaded: loaded with the theory of optics or other radiation. I disagree. One needs theory to make a microscope. You do not need theory to use one. Theory may help to understand why objects perceived with an interference-contrast microscope have asymmetric fringe around them, but you can learn to disregard that effect quite empirically to disregard that biologists know enough optics to satisfy physicist. Practice-and I mean in general doing, not looking-creates the ability to distinguish between visible artefacts of the preparation or the instrument, and the rea structure that is seen with the microscope. This practical ability breeds conviction. The ability may require some understanding of biology, although one can find first class technicians who don't even know biology. At any rate physics is simply irrelevant to the biologist's sense of microscopic reality. His observations and manipulations seldom bear any load of physical theory at all.

\section{BAD MICROSCOPES}

I have encountered the impression that Leeuwenhoek invented the microscope, and that since then people have gone on to make better and better versions of the same kind of thing. I would like to correct that idea. of thing. I whouk, hardly the first microLeeuwenhoek, hardly the first micro-
scopist, was a technician of genius. His scopist, wad a single lens, and he made a lens for each specimen to be examined. The for each specimen to be examined. The object was mounted upon a pin at just the
right distance. We don't quite know how he made such marvellously accurate drawings of his specimens. The most representative collection of his lenses-plus-specimen was given to the Royal Society in London, which lost the entire set after a century or so in what are politely referred to as suspicious circumstances. But even by that time the glue for his specimens had lost its strength and the objects had begun to fall off their and Almost certainly Leeuwenhoek got his pins. Almost certainly Leeuwenhoek got his marvelous results thanks to a secret of illumination rather than lens manufacture, and he seems never to have taught the public his technique. Perhaps Leeuwenhoek invented dark field illumination, rather than the microscope. That guess should serve as the first of a long series of possible reminders that many of the chief advances in microscopy have had nothing to do with optics. We have needed microtomes to slice specimens thinner, aniline dyes for staining, pure light sources, and, at more modest levels, the screw micrometer for adjusting focus, fixatives and centrifuges.

Although the first microscopes did create a terrific popular stir by showing worlds within worlds, it is important to note that after Hooke's compound microscope, the technology did not markedly improve. Nor did much new knowledge follow after the excitement of the initial observations. The microscope became a toy for English ladies and gentlemen. The toy would consist of microscope and a box of mounted specimens from the plant and animal kingdom. Note that a box of mounted slides migh well cost more than the purchase of the microscope itself. You did not just put drop of pond water on a slip of glass and look at it. All but the most expert would require a ready mounted slide to see anything. Indeed considering the optical aberrations it is amazing that anyone ever did see anything through a compound microscope although in fact, as always in experimenta science, a really skillful technician can do wonders with awful equipment.

There are about eight chief aberrations in bare-bones light microscopy. Two important ones are spherical and chromatic. The former is the result of the fact that you polish a lens by random rubbing. That, as can be proven, gives you a spherical surface. A light ray travelling at a small angle to the axis will not focus at the same point as a ray closer to the axis. For angles $i$ for which sin $i$ differs at all from $i$ we get no common focus of the light rays, and so a point on the specimen can be seen only as a smear through the can be seen only as a smear through microscope. This was well understood in Huygens, who also knew how to correct it in principle, but practical combinations of concave and convex lenses to avoid sphercal aberration were a long time in the makn.

Chromatic aberrations are caused by differences in wavelength between light of different colors. Hence red and blue light emanating from the same point on the specimen will come to focus at different points. A sharp red image is superimposed on a blue smear or vice versa. Although rich people liked to have a microscope about the house for entertainments, it is no wond that serious science had nothing to do with that serious science had nothing to do with the founder of We often regard Bichat as the founder of histology, the study of living issues. In 1800 he would not allow a microscope in his lab.

When people observe in conditions of obscurity each sees in his own way and according as he is affected. It is, therefore, observation of the vital properties that must guide us rather than the blurred images provided by the best of microscopes. ${ }^{9}$

No one tried very hard to make achromatic microscopes, because Newton 

had written that they are physically impossi- cause of advance was the availability of
ble. They were made possible by the advent aniline dyes for staining. Living matter is of flint glass, with refractive indices different from that of ordinary glass. A doublet of two lenses of different refractive indices can be made to cancel out the aberration perfectly for a given pair of red and ration perfectly for a given pair of red and blue wavelengths, and although the solution is imperfect over the whole spectrum, it is pretty negligible and can be improved by a triplet of lenses. The first person to get the right ideas was so secretive that he sent the specifications for the lenses of different kinds of glass to two different contractors. They both subcontracted with the same artisan, who then formed a shrewd guess that the lenses were for the same device. In due course, in 1758, the idea was pirated. A in favor of the pirate, John Doland. The High Court Judge ruled:

It was not the person who locked the invention in his scritoire that ought to profit by a patent for for the benft of the public.

The public did not benefit all that much Even up in to the 1860 s there were serious debates as to whether globules seen through a microscope were artefacts of the instrument or genuine elements of living material (They were artefacts.) Microscopes did get better and aids to microscopy improved at rather a greater rate. If we draw a graph of development we get a first high around 1660 , then a slowly ascending great leap around 1870; the next great period, which is still with us, coxt great period, which is still with us, commences about 1945. An historian has plotted this graph with great precision, using as a scale the limits of resolution of surviving instruments of different epochs. ${ }^{11}$ Making a subjective assessment of great applications of the microscope, we would draw a similar graph, except that the $1870 / 1660$ contrast would be greater. Few truly memorable facts were found out with a microscope until after 1860. The surge of new microscopy is partly due to Abbe, but the most immediate mostly transparent. The new aniline dyes made it possible for us to see microbes and much else.

\section{ABBE AND DIFFRACTION}

How do we "normally" see? Mostly we se reflected light. But if we are using a magnifrom behind, then it is transmission, or absorption, that we are "seeing." So we have the following idea: to see something through a light microscope is to see patches of dark and light corresponding to the proportions of light transmitted or absorbed. We see changes in the amplitude of light rays. I think that even Huygens knew there is something wrong with this conception, but not until 1873 could one read in print

Ernst Abbe provides the happiest exam-
ple of a rags-to-riches ple of a rags-to-riches story. Son of a spinning-mill workman, he yet learned mathematics and was sponsored through the Gymnasium. He became a lecturer in mathematics, physics, and astronomy. His optical work led him to associate. He was taken on by the small firm of Carl Zeiss in Jena, and when Zeiss died he became an owner; he retired to a life of philanthropy. Innumerable mathematical and practical innovations by Abbe turned Carl zeiss into only one.

Abbe was interested in resolution. Magnification is worthless if it "magnifies" two distinct dots into one big blur. One needs to esolve the dots into two distinct images. $G$. B. Airy, the English Astronomer Royal, had seen the point already when considering the properties of a telescope needed to distinuish twin stars. It is a matter of diffraction. The most familiar example of diffraction is the fact that shadows of objects with sharp boundaries are fuzzy. This is a consequence of the wave character of light. When light fying glass to look at a specimen illumined is something hevations by Abbe turned Carl Zeiss into travels between two narrow slits, some of the beam may go straight through, but some of and some off at an angle to the main beam, more will bend off at a larger angle: these are the first-order, second-

Abbe took as his problem how to resolve (i.e., visibly distinguish) parallel lines on a diatom. These lines are very close together and of almost uniform separation and width. He was soon able to take advantage of even more regular artificial diffraction gratings. His analysis is an interesting example of the way in which pure science is applied, for he worked out the theory for the pure case of looking at a diffraction grating, and inferred that this represents the infinite complexity of the physics of seeing a heterogeneous object with a microscope.

When light hits a diffraction grating most of it is diffracted rather than transmitted. It is emitted from the grating at the angle of first, second, or third order diffractions, where the angles of the diffracted rays are in part a function of the distances between the lines on the grating. Abbe realized that in order to see the slits on the grating, one must pick up not only the transmitted light, but also at least the first order diffracted ray. What you see, in fact, is best represented as a Fourier synthesis of the transmitted and the diffracted rays. Thus according to Abbe the image of the object is produced by the interference of the light waves emitted by the principle image, and the secondary images of the light source which are the result of diffraction.

Practical applications abound. Evidently you will pick up more diffracted rays by having a wider aperture for the objective lens, but then you obtain vastly more spherical aberration as well. Instead you can change the medium between the specimen and the lens. With something denser than air, as in the oil immersion microscope, you capture more of the diffracted rays within a given aperture and so increase the resolution of the microscope.

Even though the first Abbe-Zeiss microscopes were good, the theory was resisted for a number of years, particularly in England and America, who had enjoyed a century of dominating the market. Even by 910 the very best English microscopes, built on purely empirical experience although stealing a few ideas from although stealing a few ideas from Abbe, equipment. The expensive rial-and-error skills were craftsmen with rivalry which, only commercial or national rivalry which made some people hesitate to believe Abbe. In an American textbook of 1916 I find it stated that an alternative (and more "common sense") theory of "ordinary" vision is now once again in the ascendant and will soon scuttle Abbe! ${ }^{13}$ Resistance arose partly from surprise at what Abbe asserted, with the apparent consequence that, as quotation [A] has it, "there is and that, as quotation $[\mathrm{A}]$ has it, "there is and and macroscopic vision." If $y$ a hold (as my mor

If you hold (as my more modern quotation [B] still seems to hold), that what we see is essentially a matter of a certain sort of physical processing in the eye, then everything else must be more in the domain of optical illusion or at best of mapping. On that account the systems of Leeuwenhoek and of Hooke do allow you to see. After Abbe even the conventional light microscope is essentially a Fourier synthesizer of first or even second order diffractions. Hence you must modify your notion of seeing or hold that you never see through a seeing or hold that you never see through a erious microscope. Before reaching a conclusion on this question, we had best exam-
ine some more recent instruments.

\section{A PLETHORA OF SCOPES}

We move on to after World War II. Most of the ideas had been around during the interwar years, but did not get beyond prototypes until later. One invention is a good deal older, but it was not properly exploited for a while.

The first practical problem for the cell Thost is that most living material does not show up under an ordinary light micro- 

and relying solely on certain properties

light that we do not normally "see."

Abbe's theory of diffraction, augmented by the polarizing microscope, leads to something of a conceptual revolution. We do no have to see using the "normal" physics of seeing in order to perceive structures in living material. In fact we never do. Even in the standard case we synthesize diffracted rays rather than seeing the specimen by way of "normal" visual physics. Then the por izing microscope reminds us that there more to light than refraction, absorption and diffraction. We could use any property of light that interacts with a specimen in order to study the structure of the specimen. Indeed we study the structure of the specimen. Indeed we
could use any property of any kind of wave at could

Even when we stick to light there is lots to do. Ultraviolet microscopy doubles resolving power, although its chief interest lies in noting the specific ultraviolet absorptions that are typical of certain biologically important substances. In fluorescence microscopy the incident illumination is can-

\section{TRUTH IN MICROSCOPY}

The differential interference-contrast technique is distinguished by the following characteristics: Both clearly visible outlines (edges) within the imaged in their true profile.

So says a Carl Zeiss sales catalogue to hand. What makes the enthusiastic sales person suppose that the images produced by these several optical systems are "true"? Of course, the images are "true" only when one course, the inages are "true" only when one has learned to put aside distortions. There are many grounds for the conviction that a perceived bit of structure is real or true. One of the most natural is the most important. I shall illustrate it with my own first experience in the laboratory. ${ }^{14}$ Low-powered electron microscopy reveals small dots in red blood cells. These are called dense bodies: that means simply that they are electron dense, and show up on a transmission electron microscope without any preparations or staining whatsoever. On the barathe movements and densities of these bodies in various stages of cell developmese bodies ease, it is guessed that disease, it is guessed that they may have an important part to play in blood biology. On the other hand they may simply be artefacts of the electron microscope. One test is obvious: can one see these selfsame bodie using quite different physical techniques? In this case the problem is fairly readily solved. The low resolution electron microscope is about the same power as a high resolution light microscope. The dense bodies do not show up under every technique, but are revealed by fluorescent staining, subsequent observation by the fluorescent microscope.

Slices of red blood cell are fixed upon a microscopic grid. This is literally a grid when seen through a microscope one sees a grid each of whose squares is labelled with a capital letter. Electron micrographs are made of the slices mounted upon such configurations of dense bodies are then prepared for fluorescence microscopy. Finally compares the electron micrographs and the fluorescence micrographs. One knows that the micrographs show the same bit of the cell, because this bit is clearly in the square of the grid labelled $P$, say. In the fluorescence micrographs $P$, say. In the the same arrangement of there is exactly structure and of the seven "bodid, general cell the electron micrograph. "bodies" seen in the bodies are nicrograph. It is inferred that microdies are not an artefact of the electron Two pe.

Two physical processes-electron transmission and fluorescent re-emission-are used to detect the bodies. These processes have virtually nothing in common between them. They are essentially unrelated chunks of physics. It would be a preposterous coin cidence if time and again two completely different physical processes produced idety ical visual configurations which iden however configurations which were rather Note real structures in the cell.

Note that no one actually produces this argument from coincidence" in real life. One simply looks at the two (or preferably more) sets of micrographs from different physical systems, and sees that the dense bodies occur in exactly the same place in each pair of micrographs. That settles the matter in a moment. My mentor, Dr. Richard Skaer, had in fact expected to prove that dense bodies are artefacts. Five minutes after examining his completed experimental micrographs he knew he was wrong.

Note also that no one need have any ideas what the dense bodies are. All we know is that there are some structural features of the cell rendered visible by several techniques. Microscopy itself will never tell all about these bodies (if indeed there is anything important to tell). Biochemistry must be called in. Also, instant spectroscopic analysis of the dense body into constitutent elements is now available, by combining an electron microscope and a spectroscopic microscopes, multiple beam interference phase modulated interference, and so forth 


\section{THE ARGUMENT OF THE GRID}

Van Fraassen challenges this and related arguments for realism that deploy what Gilbert Harman calls "inference to the best explanation," or what Hans Reichenbach and Wesley Salmon call the "common cause" argument. So it may seem as if my talk of coincidence puts me in the midst of an ongoing feud. Not so! My argument is much more localized, and commits me to none of the positions of Smart or Salmon.

one of the positions of Smart or Salmon. observational and theoretical vocabulary. There may well be no theoretical vocabulary for the things seen under the microscope"dense body" means nothing else than something dense, i.e., that shows up under the electron microscope without any staining or other preparation. Secondly we are not concerned with explanation. We see the same constellations of dots whether we use an electron microscope or fluorescent staining, and it is no "explanation" of this to say that some definite kind of thing (whose nature is as yet unknown) is responsible for the persistent arrangement of dots. Thir for we have no theory whichent of dots. Thirdly rance haps most important difference is this: we

I now venture a philosopher's aside on the topic of scientific realism. Van Fraassen says we can see through a telescope because although we need the telescope to see the moons of Jupiter when we are positioned on earth, we could go out there and look at the moons with the naked eye. Perhaps that fantasy is close to fulfillment, but it is still science fiction. The microscopist avoids fantasy. Instead of flying to Jupiter he shrinks the visible world. Consider the the for world. Consider the grid that we the tiny grids are made of metal; they are barely visible to the naked eye. They are made by drawing a very large grid with pen and ink. Letters are neatly inscribed by a draftsman at the corner of each square on the grid. Then the grid is reduced photographically. Using what are now standard techniques, metal is deposited on the resulting micrograph. Grids are sold in packets, or rather tubes, of 100,250 , and 1,000. The procedures for making such grids are entirely well understood, and as reliable as any other high-quality mass production system.

In short, rather than disporting ourselves to Jupiter in an imaginary space ship, we are routinely shrinking a grid. Then we loo at he tiny disc throug almost any kind microscope and see ex actly the sam kind and letters as were drawn in the large by the first draftsman. It is impossible seriously to entertain the thought that the minute disc which I am holding by a pair of tweezers, does not in fact have the structure of a labelled grid. I know that what I see through the microscope is veridical because we made the grid to be just that way. I know that the process of manufacture is reliable, because we can check the results with the microscope. Moreover we can check the results with any kind of microscope, using any of a dozen unrelated physical processes to produce an image. Can we entertain the possibility that, all the same, this is some gigantic coincidence? Is it false that the dis is, in fine, in the shape of a labelled grid? Is it a gigantic conspiracy of thirteen totally unrelated physical processes that the large scale grid was shrunk into some non-grid which when viewed using twelve different kinds of microscopes still looks like a grid? To be an anti-realist about that grid you would have to invoke a malign Cartesian demon of the microscope.

The argument of the grid probably requires a healthy recognition of the disunity of science, at least at the phenomenological level. Light microscopes, trivially, all use light, but interference, polarizing, phase contrast, direct transmission, fluorescence, and so forth all exploi essentially unrelated phenomenological aspects of light. If the same structure can be discerned using many of these different aspects of light waves, we cannot seriously suppose that the structure is an artefact of all the different physical systems. Moreover I emphasize that all these physical systems are made by people. We as it were purify are made by people. We as it were purify some aspect of nature, isolating, say, th phase interference character of light. We design an instrument knowing in principle exactly how it will work, just because optics is so well understood a science. We spend a number of years debugging several prototypes, and finally have an off-the-shelf instrument, through which we discern a particular structure. Several other off-theshelf instruments, built upon entirely different principles, reveal the same structure.
No one, short of the Cartesian sceptic can suppose that the structure is made by the 列

It was once not only possible but perfectly sensible to ban the microscope from the histology lab on the plain grounds that it chiefly revealed artefacts of the optical system rather than the structure of fibers. That is no longer the case. It is always a problem in innovative microscopy to become convinced that what you are seeing is really in the specimen rather than seeing is really in preparation rother than an artefact of the preparation of the optics. But by 1981, as opposed to 1800 , we have a vast arsenal of ways of gaining such conviction. I emphasize only the "visual" side. Even there I am simplistic. I say that if you can see the same fundamental features of structure using several different physical systemś, you have excellent reason for saying, "that's real" rather than, "that's an artefact." It is not conclusive reason. But the situation is no different reason. But the situation is no different from ordinary vision. If black patches on the tarmac road are seen, on a spectives, but always in the same locaton one concludes that in the same location, rather thad the familiar illusiong puddles rather than the familiar illusion. One may still be wrong. One is wrong, from time to time, in microscopy, too. Indeed the sheer similarity of the kinds of mistakes made in macroscopic and microscopic perception may increase the inclination to say, simply, that one sees through a microscope.

I must repeat that just as in large scale vision, the actual "images" or micrographs are only one small part of the confidence in reality. In a recent lecture the molecular biologist G. S. Stent recalled that in the late forties or early fifties Life magazine had a full color cover of an electron micrograph, labelled, excitedly, "the first photograph of the gene." 16 Given the theory, or lack of theory, of the gene at that time, said Stent, the title did not make any sense. Only a greater understanding of what a gene is can bring the conviction of what the micrograph shows. We become convinced of the reality of bands and interbands on chromosomes 
not just because we see them, but because we formulate conceptions of what they do, what they are for. But in this respect, too, microscopic and macroscopic visions are no different: a Laplander in the Congo won't until he starts to get some idea what is in the jungle.

Thus I do not advance the argument from coincidence as the sole basis of our conviction that we see true through the microscope. It is one element, a compelling visual element, that combines with more intellectual modes of understanding, and with other kinds of experimental work. Biological microscopy without practical bio-
chemistry is as blind as Kant's intuitions in chemistry is as blind as
the absence of concepts.

\section{THE ACOUSTIC MICROSCOPE}

I here avoid the electron microscope. There is no more "the" electron microscope than "the" light microscope: all sorts of different properties of electron beams are used. A simple but comprehensive explanation requires another essay. In case, however, we have in mind too slender a diet of examples based upon the properties of visible light, let us briefly consider the most disparate kind of radiation imaginable: sound.

Radar, invented for aerial warfare, and sonar, invented for war at sea, remind us that longitudinal and transverse wave fronts can be put to the same kinds of purpose Ultrasound is "sound" of very high frequency. Ultrasound examination of the foetus in vitro has recently won well deserved publicity. Over forty years ago Soviet scientists suggested a microscope using sound of frequency 1000 times greater than audible noise. Technology has greater than audible noise. Technology has
only recently caught up to this idea. Useful only recently caught up to this idea.

prototypes are just now in operation.

The acoustic part of the microscope is relatively simple. Electric signals are converted into sound signals and then, afte interaction with the specimen, are recon- erted into electricity. The subtlety of presthe electronics rather a the acoustics. The acoustic microscope scanning device. It produces its images by converting the signals into a spatial display on a television screen, a micrograph, or, when studying a large number of cells, a videotape.

As always a new kind of scope is interesting because of the new aspects of a specimen that it may reveal. Changes in refractive index are vastly greater for sound than for light. Moreover sound is transmitted through objects that are completely opaque. Thus one of the first applications of the acoustic microscope is in metallurgy, and also in detecting defects in silicon chips. For the biologist, the prospects are also striking. The acoustic microscope is sensitive to density, viscosity, and flexibility of living matter. Moreover the very short bursts of sound used by the scanner do not immediately damage the cell. Hence one may study the ife of a cell in a quite literal way: one will be able to observe changes in viscosity and flexibility as the cell goes about its business."

The rapid development of acousic

microscopy leaves us uncertain where it will mad. A couple of years ago where it will reports carefully dear ago the research with electron microscopes; they competition with electron microscopes; they were glad to
give resolution at about the level of light scopes. Now, using the properties of sound in supercooled solids, one can emulate the resolution of electron scopes, although that is not much help to the student of living

Do we see with an acoustic microscope?

\section{LOOKING WITH A MICROSCOPE}

Do we see through a microscope? Let us first do away with the anachronistic word through. Looking through a lens was the firs step in technology, then came peering through the tube of a compound microscope. The micrograph is more to the point: we study photographs taken with a micro- scope. Thanks to the enormous focal length the windscreen. The distances are conof an electron microscope it is natural to densed and the altitude is expanded. Does view the image on a large flat surface so the pilot see the terrain? I should say so. It everyone can stand around and point to would be foolish to put in some unnatural what's interesting. Scanning microscopes word like perceive to indicate that the seein necessarily constitute the image on a screen employs an instrument Note that this case is necessarily or plate. Any image can be digitized and retransmitted on a television display or whatever. Moreover digitization is mar-
vellous for censoring noise and even reconvellous for censoring noise and even recon-
stituting lost information. Do not, however, stituting lost information. Do not, however, crystal structure, one good way to get rid of noise is to cut up a micrograph in a systematic way, paste it back together, an rephotograph it for interference contrast.

We do not in general see through a microscope; we see with one. But do we see with a microscope? It would be silly to debate the ordinary use of the word see, a word already put to innumerable uses of an entirely intellectual sort. "Now I see the point," and kindred employments in mathematics. Or consider how the physicist writes of the hypothetical entities. I quote from a lecture listing twelve fermions, or fundamental constituents of matter, including electron neutrinos, deuterons, etc. We are told that "of these fermions, only the $\mathrm{t}$ quark is yet unseen. The failure to observe $\mathrm{tt}^{\prime}$ states in $\mathrm{e}+e-$ anihilation at PETRA remains a puzzle. ..."18 Seeing and observing for this high energy physicist are a long way from the eye. (Probably seeing acquired its peculiar association with ocular vision only at the start of the nineteenth century, as is manifested in the twin doctrines called positivism and phenomenology, the philosophies that say seeing is with the eye, not the mind.)

Consider a device for low-flying jet planes, laden with nuclear weapons, skimming a few dozen yards from the surface of the earth in order to evade radar detection. The vertical and horizontal scale are both of interest to the pilot; he needs both to see a few hundred feet down and miles and miles away. So the visual information is digitized, processed, and cast on a head-up display on employs an instrument. Note that this case is not one in which the pilot could have seen he terrain by getting off the plane and tak ng a good look. There is no way of getting a look at that much landscape without an instrument.

Consider the electron diffraction microscope with which I produce images either in conventional space or in reciprocal space. Reciprocal space is, roughly speaking, conventional space turned inside out; near is far and far is near. Crystallographers often find it most natural to study their specimens in reciprocal space. Do they see them in reciprocal space? They certainly say so, and thereby call in question the Kantian and ef How far could How seeng? Suppose I take an electronic paint (I) of a cll sion screen, an accurate picture (I) of a cell that I have previously studied, say, by using a digitized and constituted image (II). Even if I am "lookng at the cell" in case (II), in (I) I am only looking at a drawing of the cell. What is the difference? The important feature is that in (II) there is a direct interaction between a wave source, an object, and a series of physical events that end up in an image of the object. To use quotation [B] once again, in case (II) we have a map of interactions cetween the specimen and the imteractions ging radiion. If the map is a good one, then (II) is This is doubless a

This is doubtless a liberal extension of the notion of seeing. We see with an acoustic microscope. We see with television, of course. We do not say that we saw an attempted assassination with the television, but on the television. That is mere idiom, inherited from "I heard it on the radio." We distinguish between seeing the television broadcast live or not. We have endless disinctions to be made with various ad 
adjectives, and even prepositions. I know of no confusion that will resu
seeing with a microscope.

\section{SCIENTIFIC/REALISM}

When an image is a map of interactions between the specimen and the image of radiation, and the map is a good one, then we are seeing with a microscope. What is a good map? After discarding or disregarding good map? After discarding or disregarding
aberrations or artefacts, the map should aberrations or artefacts, the map should
represent some structure in the specimen in represent some structure in the specimen in essentially the same two- or three-dimen-
sional set of relationships as are actually sional set of relationsh

present in the specimen.

Does this bear on scientific realism? First let us be clear that it can bear in only the modest way. I do not even argue here for the reality of objects and structure that can be discerned only by the electron microscope (That calls for another essay). I have spoken chiefly of light microscopy. I have imakn chictly of imagine a reader initilly attracted by van Fraassen and who thought that objects seen
only with light microscopes do not count as only with light microscopes do not count as
observable. That reader could change his mind, and admit such objects into the clas of observable entities. This would still leave of observable entities. This would still leave van Fraassen's anti-realism.

But if we conclude that we see with the light microscopes, does it follow that the objects we report seeing are real? No. For have said only that we should not be stuck in the nineteenth century rut of positivismcum-phenomenology, and that we should allow ourselves to talk of seing should allow ourselves to talk of seeing with implies pe. Such a recommendation implies a strong cominitment to realism about microscopy, but it begs the question at issue. This is clear from my quotation from high-energy physics, with its cheerful talk of our having seen electron neutrinos, deuterons, and so forth. The physicist is a realist, too, and he shows this by using the word see, but his usage is no argument that there
NOTES

1. From a poem, "In Commendation of the Microscope," by Henry Powers, 1664. Quoted in Saville Bradbury, The Microscope, Past and Present

2. W. Shakespeare, Romeo and Juliet, 1.4.58, $66-67$

3. William B. Carpenter, The Microscope and Its Revelations, 8th ed., revised by $\mathrm{W} . \mathrm{H}$. Dallinger, London and Philadelphia, 1899. Quoted in S. H. Gage, The Microscope, 9th ed. (Ithaca: Comstock), 21. Gage contrasts the alternative theory that microscopic vision "is with the unaided eye, the telescope and the photographic camera. This is the original view, and the one which many are favoring at the present day." 4. G. Bergmann, "Outline of an Empiricist Philosophy of Physics," American Journal of Physics, 11 (1943).248-58, 335-42. Reprinted in Readings in the Philosophy of Science, ed. H. Feigl and M. Brodbeck (New York: Appleton-Century-Crofts, 1953)

5. G. Maxwell, "The Ontological Status of Theoretical Entities," in Minnesota Studies in the Philosophy of Science, vol. 3, ed. H. Feigl and G. Maxwell (Minneapolis: University of Minnesota Press, 1962), 3-27.

6. B. C. van Fraassen, The Scientific Image (Oxford: Clarendon Press, 1980), 12.

7. I. Hacking, "Spekulation, Berechnung und die Erschaffung von Phänomemen," in Versuchungen: Aufsätze zur Philosophie Paul Feverabends, ed. P. Duerr (Frankfurt: Suhrkamp 1981), 2 Band, 126-58, esp. p. 134.

8. E. M. Slayter, Optical Methods in Biology (New York: Wiley, 1970), 261-63.

9. X. Bichat, Anatomie générale appliquéé á la physiologie et à la médecine (Paris: Brosson, Gaber et cie, 1801), 51 .

10. Quoted in Bradbury (note 1), 130
11. S. Bradbury and G. L'E. Turner, eds., effer, 1967). 12. E. Abbe, "Beitrage zur Theorie des Mikroscop und der mikroskopische

13. S. H. Gage (note 3), 11 th ed., 1916. The dropped in the 12th edition of 1917 , but the spirit is retained, including the "sui generis" does admit that "Certain very striking experiments have been devised to show the accuracy of Abbe's hypothesis, but as pointed out by many, the ordinary use of the microscope never involves the conditions realized in these experiments" (page 301). How Imre Lakatos would have delighted in this degenerating programme of preserving the naive picture of vision, complete with "monster-barring" of the striking experiments! This passage remained unchanged in essentials even in the 17th edition of 1941 .

14. I owe a particular debt of gratitude to my . who allowed me to spend a good deal of time in his cell biology laboratory in the Department of Haematological Medicine, Cambridge Univer-

15. J. J. C. Smart, Between' Science and Philoso16. I think Stent must have been referring to Life, 17 March 1947, p. 83.

17. C. F. Quate, "The Acoustic Microscope," Sciencifc. A. Qucan 241 (Oct. 1979), 62-69. R. N and C. F. Quate "Acoustic Microscopy: Jipson, tion of Subcellular Detail" "Proceedings of the National Academy of Sciences U.S.A. 76 (1979): 3325-29.

18. C. Y. Prescott, "Prospects for Polarized Electrons at High Energies," Stanford Linear vinced not by a high powered deductive theory about the cell-there is none-but because of a large number of interlocking control and create phenomena in the microscope. In short, we learn to move around in the microscopic world. Berkeley's New Theory of Vision may not be the whole truth about infantile binocular three-dimensional vision, but is surely on the right lines when we enter the new worlds within worlds that the microscope reveals to us. 